\title{
ANÁLISE COMPARATIVA DA MASTIGAÇÃO DE CRIANÇAS RESPIRADORAS NASAIS E ORAIS COM DENTIÇÃO DECÍDUA
}

\section{Comparative analysis of mastication in children with nasal and mouth breathing with first teething}

\author{
Marta Assumpção de Andrada e Silva ${ }^{(1)}$, Viviane Natalini ${ }^{(2)}$, \\ Rosana Ribeiro Ramires ${ }^{(3)}$, Léslie Piccolotto Ferreira ${ }^{(4)}$
}

\begin{abstract}
RESUMO
Objetivo: investigar as possíveis alterações, causadas pelo modo respiratório, na mastigação de crianças com dentição decídua completa, respiradoras orais e nasais. Métodos: participaram da pesquisa 46 crianças ( 23 respiradoras nasais - RN e 23 respiradoras orais - RO) matriculadas em duas escolas públicas de Educação Infantil de São Caetano do Sul. Foi aplicado um questionário aos pais para coletar dados sobre a respiração das crianças, os quais foram relacionados aos achados da avaliação oromiofuncional que constatou o modo respiratório. A amostra foi dividida nos grupos RO e RN e realizada avaliação da mastigação de pão francês (por meio de observação direta e análise de vídeo-gravação). Resultados: foi encontrada mordida frontal em 91,3\% dos RN e 82,6\% dos RO; mastigação bilateral alternada em $78,3 \%$ dos $\mathrm{RN}$ e $87,0 \%$ dos RO; movimentos verticais e rotatórios em $95,7 \%$ dos $\mathrm{RN}$ e $100 \%$ dos RO; tempo médio de mastigação de 24,10 seg. nos RN e 15,92 seg. nos RO; volume médio ingerido em $73,9 \%$ para ambos os grupos; ausência de alimento no vestíbulo bucal em $73,9 \%$ dos RN e 39,1\% dos RO; ausência de ruído em 91,3\% dos RN e $60,9 \%$ dos RO; lábios abertos em 4,3\% dos RN e 56,5\% dos RO; simetria dos músculos masseter e temporal em $100 \%$ nos dois grupos. Conclusão: houve diferença estatisticamente significante na comparação dos modos respiratórios evidenciando que o modo interfere negativamente na mastigação do respirador oral quanto aos aspectos: tempo mastigatório, sobras de alimento na cavidade oral, postura dos lábios e ruído durante a mastigação.
\end{abstract}

DESCRITORES: Mastigação; Respiração Bucal; Sistema Estomatognático; Dentição Primária

\section{INTRODUÇÃO}

O trabalho fonoaudiológico relacionado ao sistema estomatognático se restringiu basicamente à fun-

(1) Fonoaudióloga Professora Adjunto da Faculdade de Ciências Médicas da Santa Casa de Misericórdia de São Paulo; Professora Assistente da Pontifícia Universidade Católica de São Paulo e Professora nos Cursos de Especialização da Coordenadoria Geral de Especialização, Aperfeiçoamento e Extensão da Pontifícia Universidade Católica de São Paulo e do CEFAC - Saúde e Educação; Doutora em Comunicação e Semiótica pela Pontifícia Universidade Católica de São Paulo.

(2) Fonoaudióloga; Mestre em Fonoaudiologia pela Pontifícia Universidade Católica de São Paulo.

(3) Fonoaudióloga; Mestranda em Fonoaudiologia pela Pontifícia Universidade Católica de São Paulo.

(4) Fonoaudióloga Professora Titular da Pontifícia Universidade Católica de São Paulo; Coordenadora do Curso de Especialização em Fonoaudiologia - Voz da Coordenadoria Geral de Especialização, Aperfeiçoamento e Extensão da Pontifícia Universidade Católica de São Paulo; Doutora em Distúrbios da Comunicação Humana pela Universidade Federal de São Paulo. ção de deglutição durante alguns anos ${ }^{1}$. Porém, atualmente, vários autores têm mostrado a importância de outras funções como a mastigação ${ }^{2-5}$ e a respiração ${ }^{6,7}$ para o desenvolvimento e o crescimento desse sistema.

A mastigação pode ser considerada a função mais importante do sistema estomatognático, por ser a fase inicial do processo digestivo que se inicia na boca. No processo da mastigação há trituração e moagem dos alimentos, degradando-os em partículas pequenas que, logo após, ligam-se entre si pela ação misturadora da saliva, obtendo-se o bolo alimentar. Ela pode ser classificada em três fases, a saber, incisão, trituração e pulverização. Entre essas últimas duas etapas não há separação e podem se alternar ${ }^{8}$.

A mastigação é uma função aprendida e pode sofrer modificações ${ }^{9}$. Para que um indivíduo consiga mastigar, é necessário que a primeira dentição esteja inteiramente estabelecida, pois o organismo precisa de um tempo determinado para exercer tal função ${ }^{10}$. 
Além disso, a respiração oral modifica, em muitos casos, o funcionamento e as estruturas que compõem o sistema estomatognático ${ }^{6,11,12}$ e o indivíduo não pode mastigar corretamente o alimento, devido à necessidade de respirar ${ }^{13,14}$.

Quando há impedimento da respiração nasal, estabelece-se uma respiração oral que pode ser viciosa, ou seja, o indivíduo respira pela boca apesar de apresentar capacidade anatomofisiológica para respirar pelo nariz, ou orgânica quando existem alterações orgânicas obstruindo a passagem de $a^{15}$.

Independente da etiologia, a respiração pode ser afetada causando múltiplas alterações, com maior ou menor grau, em função do tempo de evolução do processo obstrutivo $^{16}$.

As causas orgânicas mais freqüentes da obstrução nasal são: hipertrofia de adenóide, rinite alérgica, desvio de septo, sinusite, bronquite, hipertrofia dos cornetos nasais e infecções crônicas das amígdalas palatinas ${ }^{14,15,17,18}$.

O respirador oral geralmente apresenta os lábios abertos com alterações de tônus, o superior pode apresentar retração ou encurtamento e o lábio inferior com eversão e aspecto seco e rachado. Observase, ainda, hipotonia e hipofunção dos músculos elevadores da mandíbula (masseteres, temporais, pterigóideos mediais) ${ }^{13,15,17,19}$ e a mandíbula encontra-se rebaixada para facilitar a entrada de ar pela boca, alongando o músculo bucinador ${ }^{20}$.

A mastigação das crianças respiradoras orais costuma ser ruidosa, desordenada, rápida e com lábios entreabertos (pela impossibilidade de respirar pelo nariz) ${ }^{21}$.

Como a necessidade respiratória é superior à de mastigar, o tempo de mastigação tem que ser considerado. Essas duas funções utilizam a mesma via, o mesmo trajeto. Além da duração diminuída, observase também a diminuição dos golpes mastigatórios, pois o indivíduo que respira pela boca evita alimentos com consistência mais dura ${ }^{22}$.

A criança respiradora oral de três a quatro anos pode apresentar alterações de oclusão, posição da mandíbula posteriorizada, boca aberta e olhar perdido. Porém, as alterações que apresentarão até a puberdade, dependerão da intensidade e da freqüência da respiração oral ${ }^{13}$.

O objetivo deste estudo foi investigar as possíveis alterações, causadas pelo modo respiratório, na mastigação de crianças com dentição decídua, respiradoras orais e nasais.

\section{MÉTODOS}

Esta pesquisa foi realizada em duas escolas públicas de Educação Infantil, da rede municipal, de São Caetano do Sul escolhidas aleatoriamente, após autorização da Diretoria de Ensino.
Foram entregues aos pais e/ou responsáveis de todas as crianças entre quatro e cinco anos e meio de idade, uma carta informativa sobre a pesquisa e um termo de consentimento que deveria ser por eles assinado, para que ficassem esclarecidos quanto ao estudo e pudessem se interessar na participação.

A delimitação da faixa etária considerou o período de dentição decídua, que se completa por volta dos três anos e não sofre modificações até os seis anos de idade, quando se dá a erupção do primeiro molar permanente ${ }^{23}$.

Foram incluídas à pesquisa, somente as crianças que apresentaram dentição decídua completa (com vinte dentes), mediante avaliação do pesquisador que não considerou o tipo de oclusão.

Foi enviado aos pais, pelas professoras, um questionário com quatro perguntas diretas sobre o modo respiratório da criança:

1) Como você acha que seu filho respira, pela boca ou pelo nariz?

2) Ele tem algum problema respiratório (como bronquite, rinite, asma, sinusite ou outros)? Caso apresente, qual?

3) A criança ronca à noite com freqüência, sim ou não?

4) Ela baba à noite com freqüência, sim ou não?

As crianças passaram por uma avaliação miofuncional oral baseada nos itens propostos na literatura ${ }^{17}$. O material utilizado na avaliação foi composto por espátulas, luvas cirúrgicas e espelho de Glatzel.

Foram avaliados os seguintes aspectos: plano sagital- cabeça (anteriorizada, posteriorizada ou adequada); plano frontal- ombros (simétricos ou assimétricos), plano dorsal- escápulas (simétricas ou assimétricas); olhos (simétricos ou assimétricos); olheiras (presentes ou ausentes); nariz (simétrico ou assimétrico); narinas (estreitas ou adequadas); bochechas (flácidas, rígidas ou adequadas); lábios (em eversão ou adequados); competência labial (competente ou incompetente); tônus dos lábios (flácidos, rígidos ou adequados); aspectos dos lábios (secos/ rachados ou adequados); simetria labial (simétricos ou assimétricos); tônus mentual (flácido, rígido ou adequado); posição habitual da língua (assoalho ou outros); altura do palato (alto ou adequado); largura do palato (estreito ou adequado); mobilidade de língua (adequada ou inadequada); mobilidade de lábio (adequada ou inadequada); e função respiratória (adequada ou alterada).

As crianças foram divididas em dois grupos a partir do cruzamento das respostas do questionário encaminhado pelos pais com as evidências encontradas na avaliação: grupo de crianças respiradoras nasais (RN) e grupo de crianças respiradoras orais (RO), com 23 crianças de ambos os sexos em cada um. Para completar 23 crianças em cada grupo, número 
estipulado pela estatística, foi avaliada uma criança $\mathrm{RN}$, em seguida uma RO, assim sucessivamente.

No grupo RO, ficaram todas as crianças que no questionário obtiveram resposta afirmativa na primeira questão, e em mais uma das outras três questões, além de apresentarem lábios incompetentes na avaliação miofuncinal oral, ou seja, lábios separados e língua posicionada no assoalho da boca, o que facilita a passagem do ar.

A avaliação da função mastigatória foi feita por meio de observação direta, uma vez que o método de avaliação funcional dirigida faz parte do trabalho do fonoaudiólogo ${ }^{2,9,24-26}$ e por gravação por meio de uma câmera de vídeo marca JVC GR AX730, apoiada em um tripé, posicionado a um metro e meio do encosto da cadeira, onde a criança permanecia sentada.

A avaliadora ofereceu a cada criança metade de um pão francês, alimento sugerido por alguns autores ${ }^{24,27} \mathrm{e}$ foi solicitado que comesse como de costume.

Para a avaliação da mastigação foi utilizado o mesmo tipo de alimento para todas as crianças, pois diferentes tipos de alimentos ingeridos podem interferir no tempo e no ciclo mastigatório ${ }^{28-30}$.

Foram observadas três mordidas para a obtenção dos dados e preenchimento do protocolo de avaliação e filmadas mais quatro mordidas do alimento para que os dados pudessem ser confirmados e conferidos posteriormente. Para cronometrar o tempo de duração de cada mordida, foi utilizado um relógio Nike Triax 10.

O protocolo utilizado para a avaliação da função mastigatória foi proposto em pesquisa realizada anteriormente ${ }^{24}$ e foram considerados os seguintes itens:

1) Mordida: frontal, lateral, fronto-lateral ou manual;

2) Forma utilizada: mastigação bilateral alternada, bilateral simultânea, unilateral, predominantemente unilateral, com dentes incisivos, amassamento com língua contra o palato;

3) Movimentos predominantes: apenas verticais, predomínio de verticais ou verticais e rotatórios;

4) Tempo de duração da mastigação: para cada criança foi cronometrado o tempo de consumo de cada porção entre o final da mordida do pão e o início da última deglutição. Foram realizadas quatro contagens e retiradas as médias de cada criança. Por fim, as médias foram somadas e divididas por 23 chegando à média de cada grupo. Foi estabelecido como lento, todo o tempo que excedesse $25 \%$ da média de seu grupo e como rápido o que apresentasse $25 \%$ abaixo do tempo médio do seu grupo.

5) Quantidade ingerida: pequena, média ou grande;

6) Sobra de alimentos: presença ou ausência;

7) Ruídos: presença ou ausência;

8) Lábios: fechados, abertos ou com alternância de fechamento;
9) Músculo masseter: força simétrica, ou seja, com mesmo grau de atividade em função ou força assimétrica;

10) Músculo temporal: força simétrica ou assimétrica.

Esta pesquisa foi avaliada e aprovada pelo Comitê de Ética do Programa de Estudos Graduados em Fonoaudiologia da PUC/SP, sob nº095/2002, e considerada como sem risco e com necessidade do consentimento livre e esclarecido.

Com relação à análise estatística, os dados foram analisados de forma descritiva e comparativa entre os grupos e aplicado o teste de Mann-Whitney com nível de significância de $5 \%(0,050)$ para possibilitar o cruzamento dos achados em cada um dos dez itens da avaliação da mastigação com o modo respiratório (nasal ou oral). Além disso, foi aplicado o teste $t$ de Student, controlado pelo Teste de Levene para Igualdade de Variâncias com nível de significância de 5\% $(0,050)$ para verificar a existência de possíveis diferenças entre as médias do tempo mastigatório dos dois grupos estudados.

\section{RESULTADOS}

Todos os resultados encontram-se descritos nas Tabelas 1 e 2 . Ao se comparar o tipo de mordida do alimento dos dois grupos estudados, constatou-se que estatisticamente não foram encontradas diferenças significantes, pois $21(91,3 \%)$ crianças do grupo RN apresentaram mordida frontal, uma (4,3\%) apresentou mordida fronto-lateral e uma $(4,3 \%)$ partiu o pão com a mão, e 19 (82,6\%) crianças do grupo RO apresentaram mordida frontal e quatro $(17,4 \%)$ mordida fronto-lateral. Nenhuma delas apresentou mordida lateral do alimento.

Em relação à forma utilizada para a trituração do alimento, foi observado que no grupo RN, 19 (82,6\%) crianças apresentaram forma bilateral alternada, uma $(4,3 \%)$ apresentou mastigação unilateral e em três crianças (13,0\%) foi observada mastigação com predomínio unilateral. No grupo RO, 20 (87,0\%) crianças apresentaram mastigação bilateral alternada e três (13,0\%), mastigação com predomínio unilateral. Nenhuma das crianças apresentou trituração do alimento com dentes incisivos ou amassamento com língua/palato. A comparação dos resultados não evidenciou diferença estatística significante, ou seja, indicou semelhança entre os dois grupos estudados em relação à forma utilizada para reduzir o alimento ingerido.

Quanto aos movimentos da mandíbula na mastigação do grupo RO, 22 (95,7\%) crianças apresentaram movimentos verticais e rotatórios e em uma $(4,3 \%)$ criança foram observados movimentos com predomínio vertical. Em nenhuma criança avaliada foram observados movimentos apenas verticais de 
mandíbula. No grupo de crianças RN, foram encontrados movimentos verticais e rotatórios nas 23 $(100 \%)$ crianças. Os dados encontrados indicam semelhança nos movimentos utilizados para a mastigação entre os dois grupos, portanto, o modo respiratório não foi um fator de diferenciação no movimento da mandíbula durante a redução do alimento entre o grupo RO e o grupo RN.

O tempo de duração da função mastigatória indicou diferença estatisticamente significativa $(p<0,001)$ na comparação da média de tempo de mastigação de cada grupo. O grupo RN teve valor médio de 24,10 segundos (desvio-padrão de 7,64) em relação ao grupo RO que apresentou 15,92 segundos (desvio-padrão de 4,24) no tempo de consumo de cada porção de alimento. Esses achados estão descritos na Tabela 2.

Quanto à quantidade de alimento ingerido na cavidade oral, há semelhança no resultado obtido na comparação dos grupos. No grupo RN, quatro $(17,4 \%)$ crianças ingeriram quantidade pequena, $17(73,9 \%)$ crianças ingeriram quantidade média e duas $(8,7 \%)$ crianças, quantidade grande em relação à cavidade oral. No grupo RO, seis $(26,1 \%)$ crianças apresentaram quantidade pequena, $17(73,9 \%)$ ingeriram quantidade média e nenhuma criança ingeriu quantidade grande de alimento.

A comparação dos resultados dos grupos $\mathrm{RO} e$ $\mathrm{RN}$, quanto à sobra de alimentos na cavidade oral, também demonstrou diferença estatisticamente significativa $(p=0,01)$. No grupo $R N$, havia presença de sobras de alimento no vestíbulo da boca em seis $(26,1 \%)$ crianças, enquanto que em $17(73,9 \%)$ não havia. No grupo RO, 14 (60,9\%) crianças apresentaram restos de alimento após a deglutição e nove $(34,8 \%)$ não.

O grupo RN apresentou ruído ao mastigar em duas $(8,7 \%)$ crianças e ausência em $21(91,3 \%)$. No grupo $\mathrm{RO}$, foi observado ruído em nove $(39,1 \%)$ e ausência em 14 (60,9\%) crianças estudadas. A comparação destes dados mostrou diferença estatisticamente significante em relação ao ruído na mastigação dos dois grupos $(p=0,01)$.

Em relação à postura dos lábios durante a mastigação, uma (4,3\%) criança do grupo RN mastigou com os lábios abertos, 17 (73,9\%) com os lábios fechados e cinco $(21,7 \%)$ ora abertos e ora fechados, enquanto que $13(65,5 \%)$ crianças do grupo RO mastigaram com os lábios abertos, duas $(8,7 \%)$ com os lábios fechados e oito $(34,8 \%)$ ora abertos e ora fechados. Essas diferenças entre os grupos foram consideradas estatisticamente significantes quanto à postura de lábios abertos ao mastigar $(p<0,001)$.

Por último, a comparação da simetria dos músculos masseter e temporal mostrou que $100 \%$ das crianças, tanto no grupo RN quanto no grupo $\mathrm{RO}$, apresentaram simetria durante a mastigação. Não houve, dessa forma, diferença estatística significante.

Tabela 1 - Comparação dos aspectos da mastigação do grupo respirador nasal (RN) e do grupo respirador oral (RO)

\begin{tabular}{|c|c|c|c|c|c|c|}
\hline Aspectos da & mastigação avaliados & $\mathrm{RN}$ & $\%$ & RO & $\%$ & $\operatorname{sig}(p)$ \\
\hline \multirow{4}{*}{ Tipo de mordida } & Frontal & 21 & 91,3 & 19 & 82,6 & 0,38 \\
\hline & Fronto-lateral & 1 & 4,3 & 4 & 17,4 & 0,16 \\
\hline & Lateral & 0 & 0 & 0 & 0 & 0,99 \\
\hline & Parte com a mão & 1 & 4,3 & 0 & 0 & 0,99 \\
\hline \multirow{6}{*}{$\begin{array}{l}\text { Forma utilizada } \\
\text { para a trituração } \\
\text { do alimento }\end{array}$} & Bilateral alternada & 18 & 78,3 & 20 & 87,0 & 0,99 \\
\hline & Bilateral simultânea & 1 & 4,3 & 0 & 0 & 0,99 \\
\hline & Unilateral & 1 & 4,3 & 0 & 0 & 0,31 \\
\hline & Predomínio unilateral & 3 & 13,0 & 3 & 13,0 & 0,99 \\
\hline & Com dentes incisivos & 0 & 0 & 0 & 0 & 0,99 \\
\hline & Amassa com língua/palato & 0 & 0 & 0 & 0 & 0,99 \\
\hline \multirow{3}{*}{$\begin{array}{l}\text { Movimentos } \\
\text { mandibulares }\end{array}$} & Apenas verticais & 0 & 0 & 0 & 0 & 0,99 \\
\hline & Predominio de verticais & 1 & 4,3 & 0 & 0 & 0,31 \\
\hline & Verticais e rotatórios & 22 & 95,7 & 23 & 100 & 0,31 \\
\hline \multirow{3}{*}{$\begin{array}{l}\text { Mediana do } \\
\text { tempo de } \\
\text { mastigação }\end{array}$} & Lento & 4 & 17,4 & 3 & 13 & 0,68 \\
\hline & Médio & 14 & 60,9 & 15 & 65,2 & 0,76 \\
\hline & Rápido & 5 & 21,7 & 5 & 21,7 & $>0,99$ \\
\hline \multirow{3}{*}{$\begin{array}{l}\text { Quantidade de } \\
\text { alimento ingerida }\end{array}$} & Pequena & 4 & 17,4 & 6 & 26,1 & 0,48 \\
\hline & Média & 17 & 73,9 & 17 & 73,9 & $>0,99$ \\
\hline & Grande & 2 & 8,7 & 0 & 0 & 0,15 \\
\hline \multirow{2}{*}{ Sobra de alimento } & Presente & 6 & 26,1 & 14 & 60,9 & $0,01^{*}$ \\
\hline & Ausente & 17 & 73,9 & 9 & 39,1 & $0,01^{*}$ \\
\hline \multirow{2}{*}{$\begin{array}{l}\text { Ruido ao } \\
\text { mastigar }\end{array}$} & Presente & 2 & 8,7 & 9 & 39,1 & $0,01^{*}$ \\
\hline & Ausente & 21 & 91,3 & 14 & 60,9 & $0,01^{*}$ \\
\hline
\end{tabular}




\begin{tabular}{ccccccc} 
& Abertos & 1 & 4,3 & 12 & 52,2 & $<0,001^{*}$ \\
Postura dos & Fechados & 17 & 73,9 & 2 & 8,7 & 0,20 \\
lábios & Ora abertos/ora fechados & 5 & 21,7 & 9 & 39,1 & 0,99 \\
Simetria do & Simétrico & 23 & 100 & 23 & 100 & $>0,99$ \\
músculo masseter & Assimétrico & 0 & 0 & 0 & 0 & $>0,99$ \\
Simetria do & Simétrico & 23 & 100 & 23 & 100 & $>0,99$ \\
músculo temporal & Assimétrico & 0 & 0 & 0 & 0 & $>0,99$ \\
\hline
\end{tabular}

Teste utilizado: Mann-Whitney com nível de significância de 5\% $(0,050)$

Tabela 2 - Comparação do tempo médio mastigatório do grupo respirador nasal (RN) e do grupo respirador oral (RO)

\begin{tabular}{cccccc}
\hline Variável & Modo respiratório & $\mathrm{n}$ & Média (seg) & Desvio-padrão & Significância (p) \\
\hline \multirow{2}{*}{ Tempo mastigatório } & $\mathrm{RN}$ & 23 & 24,10 & 7,64 & $<0,001^{*}$ \\
& $\mathrm{RO}$ & 23 & 15,92 & 4,24 & $<$ \\
\hline
\end{tabular}

Teste utilizado: t de Student, controlado pelo Teste de Levene para Igualdade de Variâncias com nível de significância de 5\% $(0,050)$

\section{DISCUSSÃO}

Durante a avaliação das crianças selecionadas, várias foram as dificuldades com relação ao comportamento, posicionamento na cadeira e compreensão das ordens devido a pouca idade do grupo, exigindo em muitos momentos a retomada e esclarecimento da ordem

Os resultados não foram separados por sexo para a análise, porque o objetivo principal deste estudo era analisar as diferenças entre as crianças respiradoras orais e nasais independente do sexo. Além disso, alguns autores constataram que não há diferença entre a mastigação de meninas e meninos no período intertransicional da dentição mista ${ }^{24,25} \mathrm{e}$ outro estudo mostrou que não há interferência do sexo no tempo e no número de golpes mastigatórios em crianças entre quatro e cinco anos de idade ${ }^{28}$.

As crianças não foram separadas por idade para a obtenção dos resultados, pois a faixa etária não foi a questão a ser averiguada, e sim, a fase de dentição em que se encontravam. Deveriam apresentar dentição decídua completa, isto é, as mesmas características dentárias.

Com relação aos achados referentes ao tipo de mordida do alimento, os dois grupos pesquisados (RN e RO) estão de acordo com autores que referem que o corte do alimento deve ser feito com os incisivos ${ }^{2,31}$.

Não foram encontrados na literatura consultada dados relacionados à comparação da forma utilizada para a trituração do alimento entre grupos respirado- res orais e nasais. Contudo, a forma utilizada para a mastigação do alimento da faixa etária dos grupos estudados está de acordo com alguns estudos $2,26,32$.

Entretanto, esses achados não estão de acordo com outros dois estudos ${ }^{33,34}$ os quais encontraram mastigação unilateral de forma predominante ou exclusiva. Em uma dessas pesquisas, a mastigação unilateral foi encontrada em $87 \%$ da amostra de 85 crianças entre dois e sete anos e três meses de idade com dentição decídua e mista com oclusão normal, embora os alimentos utilizados fossem côco e pipoca ${ }^{33}$. Na outra pesquisa, $75 \%$ da amostra formada por 20 crianças entre quatro e cinco anos com oclusão dentária normal apresentaram mastigação unilateral ${ }^{34}$

Os dois grupos pesquisados neste estudo apresentaram dentição decídua completa, fase em que as crianças apresentam condições necessárias para executar a mastigação com padrão próximo ao do adulto ${ }^{35}$.

A forma similar de mastigar pode ser justificada pela semelhança na dentição e na musculatura das crianças estudadas. A respiração oral pode trazer alteração nas estruturas do sistema estomatognático, dependendo do grau de severidade da obstrução nasal e do tempo de interferência ${ }^{15}$.

Não foram encontrados, na literatura consultada, trabalhos que mostrassem relação entre o modo de morder o alimento e o modo respiratório. A respiração oral, neste caso, ainda não teve tempo suficiente para causar alterações musculares e conseqüente- 
mente na forma da arcada dentária, o que poderia modificar o modo de morder. A semelhança na mordida era esperada, por um lado, pois os dois grupos se encontravam em fases dentárias iguais. Entretanto, com o crescimento associado à dificuldade respiratória, talvez a forma de mastigar pudesse se mostrar diferente entre os grupos.

Quanto aos movimentos da mandíbula na mastigação, as crianças com dentição decídua completa que participaram desta pesquisa deveriam apresentar movimentos mais complexos ${ }^{36}$, porém são necessárias condições anatômicas favoráveis.

Estas crianças deveriam apresentar relações mastigatórias corretas ${ }^{37}$. Quanto ao movimento da mandíbula, os dados dos dois grupos estão de acordo com a literatura ${ }^{31}$.

Um estudo realizado mostrou porcentagem não significante de movimentos mastigatórios com predomínio vertical. Porém, foi verificado que a porcentagem de crianças que apresentaram movimentos estabilizados, isto é, movimentos horizontais e rotatórios foi reduzida ${ }^{26}$. Esses achados foram contrários a esta pesquisa, em que o movimento vertical e rotatório teve alta porcentagem nos dois grupos estudados.

Em outro estudo, 80\% do grupo pesquisado apresentou movimento mais verticalizado. Esse fato foi associado aos lábios entreabertos durante a mastigação ${ }^{32}$. Esses dados não estão de acordo com este estudo, pois as alterações quanto à postura de lábios encontradas nas crianças $\mathrm{RO}$, não indicaram relação com os movimentos da mandíbula durante a mastigação desse grupo. Os movimentos da mandíbula do grupo RO, provavelmente, correspondem ao padrão esperado pelo fato de que a postura alterada dos lábios ainda não tenha tido tempo de interferir na função mastigatória.

Com relação ao tempo de duração da função mastigatória, o resultado encontrado nesta pesquisa está de acordo com alguns autores ${ }^{21,22}$, que relatam que o tempo da mastigação do indivíduo respirador oral deve ser menor, ou seja, a mastigação é mais rápida do que o indivíduo que respira pelo nariz.

A criança que não respira pelo nariz deve manter livre a passagem de ar pela boca para que consiga respirar. Ao ingerir o alimento, tem necessidade de degluti-lo rapidamente para liberar a passagem de ar pela boca para voltar a respirar. Para isso, a trituração e a moagem do alimento são mais rápidas e o tempo que o alimento fica na boca até o momento da deglutição é mais curto.

Quanto à quantidade de alimento ingerido na cavidade oral, é importante observar que no grupo respirador oral nenhuma criança ingeriu quantidade grande de alimento. Esse fato pode estar relacionado ao tempo curto de mastigação do indivíduo respirador oral. Para tentar ser mais eficiente e para liberar a cavidade oral mais rapidamente para respirar, prefere ingerir porções médias ou pequenas.

O tamanho do alimento ingerido foi relacionado ao tamanho da cavidade oral de cada criança, isto é, o alimento foi observado e analisado dentro da boca da criança logo após ser mordido, levando-se em conta a proporção do alimento em relação à cavidade oral.

A comparação dos resultados dos grupos RO e $\mathrm{RN}$, quanto à sobra de alimentos na cavidade oral, demonstrou diferença estatisticamente significativa, o que pode ser justificado pelo funcionamento inadequado do músculo bucinador, que é responsável pela recondução do alimento às faces oclusais ${ }^{38}$.

No indivíduo respirador oral, esse músculo pode estar alongado e com o tônus prejudicado, devido ao freqüente rebaixamento da mandíbula ${ }^{20}$. Em uma pesquisa realizada em 34 crianças, não foi observada sobra de alimentos no vestíbulo da boca em $94,12 \%$, porém a amostra foi composta apenas por crianças sem alterações no sistema estomatognático ${ }^{24}$.

Ao comparar a presença de ruído ao mastigar, entre o grupo RN e o grupo RO, foram encontradas diferenças estatisticamente significativas. Este dado está de acordo com a literatura consultada ${ }^{21,31}$, na qual foi observada ausência de ruído na mastigação do indivíduo respirador nasal e presença do mesmo no respirador oral. A presença significativa do ruído no grupo RO pode ser justificada pela postura aberta dos lábios, forma utilizada por grande parte desses indivíduos durante a função mastigatória.

Em relação ao posicionamento dos lábios durante a mastigação, houve concordância desta pesquisa com a literatura consultada ${ }^{21,31}$, que referiu como padrão, que os lábios devem estar fechados e, no indivíduo respirador oral, os lábios encontram-se abertos.

Quanto aos lábios abertos durante a mastigação, foram observadas diferenças significativas entre as crianças respiradoras nasais e as crianças respiradoras orais. Esta diferença pode ser justificada pela necessidade que o respirador oral tem de manter os lábios abertos ${ }^{13,15,17,26}$ com freqüência, para facilitar a passagem de ar, mesmo durante a função mastigatória. Portanto, a diferença estatística na comparação do posicionamento dos lábios entre os grupos era esperada.

A comparação da simetria dos músculos masseter e temporal indicou que o modo respiratório não interferiu, até esta fase, na simetria dos músculos das crianças. Talvez não tenha interferido devido à duração da mastigação do respirador oral ser realizada em menor tempo. Na literatura, não foram encontrados dados comparativos com relação à simetria dos músculos em indivíduos respiradores nasais e respiradores orais e sua possível relação com o tempo mastigatório. 
Com os achados deste estudo fica claro que no trabalho com a mastigação, na clínica fonoaudiológica, deve se levar em conta a idade e as características dentárias apresentadas pelo indivíduo. Informações quanto aos hábitos alimentares são fundamentais para a avaliação do modo respiratório e do sistema estomatognático em sua totalidade, pois dados encontrados na investigação da mastigação não podem ser considerados e analisados isoladamente.

Além disso, faz-se necessária a realização de outros estudos comparativos entre crianças respiradoras orais e nasais em outra fase dentária, pois alterações musculares mais significativas encontradas em crianças que respiram pela boca por mais tempo, poderiam modificar ainda mais o desempenho da função mastigatória.

Dessa forma, vale salientar a importância de se ampliarem estudos que relacionem as funções de mastigação e respiração, pois, durante a realização deste estudo, foi constatada a dificuldade de encontrar pesquisas que relacionassem as duas funções.

\section{CONCLUSÃO}

Na comparação da mastigação entre crianças respiradoras nasais e crianças respiradoras orais, ambas com dentição decídua foram encontradas semelhanças com relação aos seguintes fatores: mor- dida frontal do alimento, mastigação bilateral alternada, movimentos verticais e rotatórios da mandíbula durante a mastigação, quantidade média de alimento, simetria na contração dos músculos masseter durante a mastigação e simetria na contração dos músculos temporal durante a mastigação.

As diferenças encontradas entre esses mesmos grupos foram: tempo de mastigação, pois o grupo $\mathrm{RO}$ apresentou mastigação mais rápida que o RN; ausência de restos de alimento no grupo RN e presença de restos no vestíbulo da boca no grupo RO; ausência de ruído no grupo $\mathrm{RN}$ e presença de ruído durante a mastigação no grupo RO; e lábios fechados no grupo RN e abertos no grupo RO.

Pode-se concluir que a respiração oral interfere em determinados aspectos da função mastigatória. Desta forma é de extrema importância que durante a avaliação da mastigação seja levado em conta o modo respiratório de cada indivíduo.

\section{AGRADECIMENTOS}

Aos integrantes do LaborVox ( laboratório da Linha de pesquisa em Voz do Programa de Pós graduação em Fonoaudiologia da PUC/SP) pela colaboração.

A CAPES pelo auxílio financeiro e pelo incentivo à pesquisa.

\begin{abstract}
Purpose: to investigate the possible alterations caused by breathing modus in mastication in a group of children with complete first teething, nasal and mouth breathing. Method: 46 children took part in this investigation ( 23 children were nasal breathing- NB and 23 children mouth breathing- MB). Children were enrolled in two public kindergartens in São Caetano do Sul. Their parents were asked to fill out a form in order to collect information about their children's breathing. This data was related with oral miofunctional evaluation to check the children's breathing modus. NB and MB groups were formed and a mastication function evaluation was carried out by observation means and videoing the children while they were masticating French bread. Results: fontal bite: NB, 91.3\%; MB, 82.6\%. Alternate bilateral mastication: NB, 78.3\%; MB, 82.0\%. Vertical and rotating movements: NB, 95.7\%; MB, 100\%. Average time of mastication of NB group: 24.0 sec.; average time of MB group: $15.9 \mathrm{sec}$. Symmetry of average volume taken: NB, 73.9\%; MB, 73.9\%. Without any residue of food: NB, 73.9\%; MB, 39.1\%. Absence of noise: NB, $91.3 \%$; MB, $60.9 \%$. Open lips: NB, $4.3 \%$; MB, 56.5\%; Symmetry of masseter and temporalis muscles: NB, 100\%; MB, 100\% in both groups. Conclusion: significant statistical difference occurred in breathing modus comparison, negatively affecting some aspects of mouth breathing's mastication, which were mastication time, residue of food in the oral cavity, lips posture and noise during mastication.
\end{abstract}

KEYWORDS: Mastication; Mouth Breathing; Stomatognathic System; Dentition, Primary

\section{REFERÊNCIAS}

1. Padovan B. Deglutição atípica. Rev Ortodontia. 1976; 9. Separata.

2. Costa GB. Mastigação infantil: enfoque fonoaudiológico. Fono Atual. 2000; 3:15-20.

3. Duarte LIM. Relação entre má oclusão e mastigação. Rev Soc Bras Fonoaudiol. 2001; 1:46-51.

4. Duarte LIM. Respiração e mastigação: um estudo comparativo entre dois grupos, com e sem interven-

Rev CEFAC, São Paulo, v.9, n.2, 190-8, abr-jun, 2007 
ção fonoaudiológica. [mestrado]. São Paulo (SP): Pontifícia Universidade Católica de São Paulo; 2002.

5. Bacha SMC, Ríspoli CFM. Mastigação nos distúrbios miofuncionais orais. In: Marchesan IQ, Bolaffi C, Gomes ICD, Zorzi JL, organizadores. Tópicos de fonoaudiologia. Rio de Janeiro: Revinter; 2003. p. 199-208.

6. Krakauer LH, Guilherme H. Relação entre respiração bucal e alterações posturais em crianças: uma análise descritiva. Rev Soc Bras Fonoaudiol. 1998; 1:18-25.

7. Lessa FCR, Enoki C, Feres MFN, Valera CP, Lima WTA, Matsumoto MAN. Influência do padrão respiratório na morfologia craniofacial. Rev Bras Otorrinolaringol. 2005; 71(2):156-60.

8. Douglas CR. Fisiologia da mastigação. In: Douglas CR. Tratado de fisiologia aplicada às ciências da saúde. São Paulo: Robe; 1994. p. 857-85.

9.Bianchini EMG. Mastigação e ATM-Avaliação e terapia. In: Marchesan IQ, organizadora. Fundamentos em fonoaudiologia: aspectos clínicos da motricidade oral. Rio de Janeiro: Guanabara Koogan; 1998. p. 37-49.

10. Simões WA. Ortopedia funcional dos maxilares vista através da reabilitação neuro-oclusal. São Paulo: Santos; 1985. 794 p.

11. Valera FC, Travitzki LV, Mattar SE, Matsumoto MA, Elias AM, Anselmo-Lima WT. Muscular, functional and orthodontic changes in pre school children with enlarged adenoids and tonsils. Int $\mathrm{J}$ Pediatr Otorhinolayngol. 2003; 67(7):761-70.

12. Bicalho GP, Motta AR, Vicente LCC. Avaliação da deglutição em crianças respiradoras orais. Rev CEFAC. 2006; 8(1):50-5.

13. Breuer J. El paciente respirador bucal. Rev Asoc Odontol Argent. 1989; 77:102-6.

14. Marchesan IQ, Krakauer LH. A importância do trabalho respiratória na terapia miofuncional. In: Marchesan IQ, Bolaffi C, Gomes ICD, Zorzi JL, organizadores. Tópicos de fonoaudiologia. São Paulo: Lovise; 1995. p.155-60.

15. Jabur LB. Avaliação fonoaudiológica. In: Ferreira FV, organizador. Ortodontia: diagnóstico e planejamento clínico. São Paulo: Artes Médicas; 1998. p. 283-309.

16. Novaes MSP, Vigorito JW. Respiração bucal: aspectos gerais e principais metodologias empregadas para avaliação. Ortodontia. 1993; 26:43-50.

17. Marchesan IQ. Avaliação e terapia dos problemas da respiração. In: Marchesan IQ, organizadora. Fundamentos de fonoaudiologia: aspectos clínicos da motricidade oral. Rio de Janeiro: Guanabara Koogan; 1998. p. 23-36.

18. Lusvarghi L. Identificando o respirador bucal. Rev APCD. 1999; 53:265-72.

19. Soncini F, Dornelles S. Respiração: contradições entre as informações dos pais e os resultados da avaliação fonoaudiológica. Fono Atual. 2000; 11:46-51. 20. Aragão W. A saliva do respirador bucal. J Bras
Odontol Clín. 1997; 1:65-7.

21. Junqueira $P$. Conhecendo alguns distúrbios você pode preveni-los. In: Junqueira P. Amamentação, hábitos orais e mastigação: orientação, cuidados e dicas. Rio de Janeiro: Revinter; 2000. p. 23-6.

22. Tomé MC, Marchiori SC, Pimentel R. Mastigação: implicações na dieta alimentar do respirador bucal. J Bras Fonoaudiol. 2000; 3:60-5.

23. Köhler GI. Desenvolvimento da oclusão. In: Petrelli $E$, organizador. Ortodontia para fonoaudiologia. Paraná: Lovise; 1994. p. 67-79.

24. Motta AR. Descrição da mastigação no período intertransicional da dentição mista. [mestrado]. São Paulo (SP): Pontifícia Universidade Católica de São Paulo; 2002.

25. Motta AR. A mastigação no período intertransicional da dentição mista. Rev Dental Press Ortodon Ortop Facial. 2002; 7(5):77-87.

26. Soncini F, Dornelles S, Meurer E, Teixeira S. Perfil de crianças de 4 anos em relação ao padrão alimentar habitual, hábitos orais e função mastigatória. In: Marchesan IQ, Bolaffi C, Gomes ICD, Zorzi JL, organizadores. Tópicos de fonoaudiologia. Rio de Janeiro: Revinter; 2002, 2003. p. 209-20.

27. Marchesan IQ. Avaliando e tratando o sistema estomatognático. In: Campiotto $A R$, et al, organizadores. Tratado de fonoaudiologia. São Paulo: Roca; 1997. p. 763-80.

28. Schwartz JL, Niman CW, Gisel EG. Chewing cycles in 4- and 5- year-old normal children: an index of eating efficacy. Am J Occup Ther. 1984; 38(3):171-5.

29. Schwaab LM, Niman CW, Gisel EG. Comparacion of chewing cycles in 2-3-4 and 5-year-old normal children. Am J Occup Ther. 1986; 40(1):40-3.

30. Gisel EG. Chewing cycles in 2-to 8-year- old normal children: a developmental profile. Am J Occup Ther. 1988; 42(1):40-6.

31. Junqueira P. Avaliação miofuncional. In: Marchesan IQ, organizadora. Fundamentos em fonoaudiologia: aspectos clínicos da motricidade oral. Rio de Janeiro: Guanabara Koogan; 1998. p. 13-21. 32. Meurer E, Veiga L, Capp E. Hábitos mastigatórios e de deglutição em crianças de 3 a 5 anos. Rev Soc Bras Fonoaudiol. 1998; 3:29-34.

33. Santiago Junior O. Incidência de mastigação unilateral em crianças com dentição decídua e dentição mista em estágio inicial com alimentos fibrosos e macios. Rev Fac Odontol. 1994; 35:28-31.

34. Amaral DB. Mastigação unilateral x oclusão normal: um estudo sobre sua ocorrência em crianças de 4 a 5 anos. Rev CEFAC. 2000; 2:23-30.

35. Verzoni LDN, Limongi SCO. A inter-relação entre os desenvolvimentos neuropsicomotor, cognitivo, de linguagem e do sistema miofuncional oral no período sensório-motor, por meio da análise de dois casos de crianças portadoras de lesão cerebral. In: Limongi SCO, organizadora. Fonoaudiologia e pesquisa: sé- 
rie atualidades em fonoaudiologia. São Paulo: Lovise; 1998. p. 63-110.

36. Molina OF. Fisiopatologia craniomandibular (oclusão e ATM). São Paulo: Pancast; 1989. 677 p. 37. Moyers RE, Carlson DS. Maturação da neuromusculatura orofacial. In: Enlow DH, Hans MG, organizadores. Noções básicas sobre crescimento facial. São Paulo; 1998. p. 233-40.

38. Felício CM. Sistema estomatognático e funções. In: Felício CM, organizadora. Fonoaudiologia aplicada a casos odontológicos: motricidade oral e audiologia. São Paulo: Pancast; 1999. p. 15-48.

RECEBIDO EM: 27/09/2006

ACEITO EM: 01/03/2007

Endereço para correspondência:

Rua Navarro de Andrade, 71 apt. 5

São Paulo - SP

CEP: 05418-020

Tel/ fax: (11) 30311345/ (11) 99576530

E-mail: martaandrada@uol.com.br

Rev CEFAC, São Paulo, v.9, n.2, 190-8, abr-jun, 2007 